\title{
Relation of Neurological Findings after Cardiac Arrest to Outcome
}

\author{
JOHN O. WILLOUGHBY, BRIAN G. LEACH
}

British Medical fournal, 1974, 3, 437-439

\section{Summary}

Routine neurological examination of patients one hour after cardiac arrest seems to be of value in determining the prognosis for life and likelihood of intellectual impairment.

In 48 patients 53 episodes of cardiac arrest were followed by serial neurological examinations. Patients were divided into two groups according to neurological findings one hour after cardiac arrest. Patients in group 1 were unresponsive or at most responded in a reflex fashion to painful stimuli at one hour; these patients died or survived with intellectual damage. Patients in group 2 responded purposefully at one hour and survived without neurological damage. These patients commonly showed transient confusional states and a variety of other non-focal abnormalities, and focal signs were seen occasionally.

\section{Introduction}

The final neurological outcome of survivors of cardiac arrest is generally considered to be satisfactory (Johnson et al., 1967; McNamee, et al., 1970; Dobson et al., 1971). Neurological recovery is in doubt in the early postcardiac arrest state, and management and advice to relatives depend on assessments made during this period (Lancet, 1973). The criteria which have been used to gauge outcome are: duration of anoxia, duration of postanoxic coma (Bokonjic and Buchthal, 1961) the electroencephalogram (Hockaday et al., 1965; Pampiglione and Harden, 1968; Binnie et al., 1970; Brierley et al., 1971) and clinical examination.

It is generally considered that the duration of anoxia best determines outcome, but in practice it is rare for the exact duration of anoxia to be known. Any accurately timed anoxic period is also likely to be brief as immediate resuscitative action is normally taken, and survivors do not usually constitute a prognostic problem.

Bokonjic and Buchthal (1961) found that in $90 \%$ of patients whose postanoxic coma lasted less than 48 hours clinical recovery was complete. In most clinical situations, however, major management decisions are made while the duration of postanoxic coma is still unknown.

The electroencephalogram has been used most successfully to predict outcome by Binnie et al. (1970), but it is impracticable to perform electroencephalography routinely in the intensive care unit, where good quality records are hard to obtain. Furthermore, emergency recordings are difficult to organize within the tight schedule of a hospital E.E.G. unit.

Because the usual means for predicting outcome have major limitations, a clinical method of assessment seemed to warrant further consideration. A prospective survey was therefore planned to describe neurological features present after car-

\footnotetext{
Department of Neurology, Royal Adelaide Hospital, Adelaide, South Australis

JOHN O. WILLOUGHBY, M.B., M.R.A.C.P., Senior Registrar (Present JOHN O. WILLOUGHBY, M.B., M.R.A.C.P., Senior Registrar (Present address:

Canada)
BRIAN G. LEACH, B.SC., PH.D., Statistician
}

diac arrest and to relate these to outcome. The results suggest that early neurological assessment is of great predictive value.

\section{Patients and Methods}

All cases of successful resuscitation after cardiac arrest in a large general hospital were notified to one of us (J.O.W.) and the patients personally examined at one, four, 24, and 48 hours after cardiac arrest. All patients considered in the series had electrocardiogram documentation of asystole or ventricular fibrillation at some stage. For patients who had more than one cardiac arrest, data are given for the longest single episode, and those who had another arrest after any neurological assessment were treated as new cases. A planned protocol for neurological examination was used to enable ready analysis of data.

Standard neurological tests of cortical, brain-stem, and motor system function were performed. Cortical function was measured by testing the level of consciousness, memory, orientation, vision, and speech. Brain-stem function was estimated by testing pupillary reactions, ocular movements, corneal reflexes, respiratory pattern, and gag reflex. Motor function was estimated from type of movements, posture, tone, plantar responses, tendon reflexes, and co-ordination. Ocular movements in unconscious patients-that is, oculocephalic and oculovestibular reflexes-breathing patterns, and motor system postures were tested as recommended by Plum and Posner (1972).

Final assessments were performed from two weeks after cardiac arrest, when relatives were also interviewed for their opinion of the physical and mental abilities of the patient.

\section{Results}

A total of 53 episodes of cardiac arrest were documented in 48 patients. The age distribution of these patients and the age of the deaths are shown in table I. Cardiac arrests were due to myocardial infarction in 28 patients and cardiac failure in six. The arrest occurred after surgery in six patients, and the aetiology was metabolic in three patients, respiratory in one, and unknown in four. Some patients who had been under anaesthesia and those whose cases were complicated by heart block were not included in the series because satisfactory neurological examinations could not be performed at one hour.

Thirty-four patients survived to the final assessment. Twenty-five were neurologically normal and performed normally in their social setting. One patient suffered a dominant temporoparietal infarct during convalescence, which prevented reliable final assessment. The remaining eight patients survived with varying degrees of dementia. By correlating outcome with neurological findings at one hour two distinct groups emerged.

GROUP 1

The 18 patients in the first group were unresponsive or res- 
TABle I-Age Distribution and Deaths in 48 Patients who suffered Cardiac Arrest

\begin{tabular}{|c|c|c|c|c|c|c|c|c|c|c|c|}
\hline Age (years): & $25-30$ & -35 & -40 & -45 & -50 & -55 & -60 & -65 & -70 & -75 & -80 \\
\hline $\begin{array}{l}\text { No. of Patients } \\
\text { No. of Deaths }\end{array}$ & 1 & & $\begin{array}{l}2 \\
1\end{array}$ & $\begin{array}{l}4 \\
1\end{array}$ & 2 & $\begin{array}{l}2 \\
1\end{array}$ & $\begin{array}{l}5 \\
1\end{array}$ & $\begin{array}{r}12 \\
4\end{array}$ & $\begin{array}{r}10 \\
3\end{array}$ & $\begin{array}{l}8 \\
1\end{array}$ & 2 \\
\hline
\end{tabular}

TABLE II-Status of Group 1 Patients who survived with Intellectual Impairment

\begin{tabular}{|c|c|c|c|c|}
\hline Case No. & Age (Years) & & Status & $\begin{array}{l}\text { Time since } \\
\text { Cardiac Arrest }\end{array}$ \\
\hline $\begin{array}{l}1 \\
2 \\
3 \\
4 \\
5 \\
6 \\
7 \\
8\end{array}$ & $\begin{array}{l}72 \\
46 \\
37 \\
55 \\
64 \\
66 \\
65 \\
69\end{array}$ & $\begin{array}{l}\text { Alive } \\
\text { Dead } \\
\text { Alive } \\
\text { Alive } \\
\text { Dead } \\
\text { Dead } \\
\text { Alive } \\
\text { Alive }\end{array}$ & $\begin{array}{l}\text { Severely demented, seizures } \\
\text { Persistent vegetative state } \\
\text { Poor memory, needs help at home } \\
\text { Works under supervision } \\
\text { Impaired memory } \\
\text { Severely demented, delirious } \\
\text { Severe impairment of memory } \\
\text { Severely demented, recovering cortical blindness }\end{array}$ & $\begin{array}{l}18 \text { months } \\
3 \text { "" } \\
16 \\
14 " \\
7 \\
2 \text { weeks } \\
11 \text { months } \\
6\end{array}$ \\
\hline
\end{tabular}

ponded to painful stimuli only in a reflex fashion. Ten patients died and eight survived with intellectual impairment. The causes of death were neurological in six patients, arrhythmic in three, and "metabolic" in one. Only one patient who died had made any significant neurological recovery before death. The subsequent status of patients surviving with intellectual impairment is shown in table II.

Patients in this group showed the following patterns of response to painful stimuli: decerebrate posturing (4), decorticate posturing (9), and complete inactivity (5). In many instances, however, these patterns were not complete. One unresponsive patient showed akinetic mutism, being speechless and motionless, yet the eyes were open and apparently alert, though they failed to follow moving objects. Brain-stem function was also often impaired in this group, and 12 patients showed abnormal findings on three or more criteria.

In later examinations some group 1 patients were found to have motor behaviour of special interest. Bizarre posturing was seen in six cases, which was stereotyped and inappropriate and readily evoked by a painful stimulus though it occasionally appeared spontaneously. It was usually different from the postures seen in other patients. Two patients adopted a "curled-up" posture with one arm extended, and in the others various upper limb positions alone were consistently adopted. In none of these cases was the posture of the tonic neck reflex adopted or elicitable. In patients who died because of their neurological disturbance respiratory failure and deteriorating motor-system findings were usually present.

\section{GROUP 2}

The 30 patients in the second group were not in deep coma and comprised 25 who were conscious, three who were rouseable, and two who were unconscious but responded to painful stimuli in a purposeful way. Twenty-six survived and 25 were intellectually unchanged, while one patient could not be assessed accurately because a dominant parietal lobe infarct occurred before final examination. The causes of death were arrhythmic in three patients, metabolic in one. Only one patient who died was not fully conscious terminally.

It was uncommon even for the 25 conscious patients to be neurologically normal at the first assessment. Abnormalities are listed in table III. Confusional states varied in degree from violent restlessness and non-cooperation to mild disorientation in time. Speech disorders consisted mainly of slurring dysarthrias, but some patients were dysphasic. A striking finding was a transient but marked increase in signs in those six patients who had a pre-existing neurological deficit. No patient in group 2 had abnormalities of three or more criteria of brain-stem function.

Some group 2 patients had findings of special interest. Two showed hemianopic field defects, which cleared within 24 hours. One had a complete isolated defect of retentive memory, which abruptly resolved on the third day. Chorea, tremor, and myoclonus were each present in isolated cases.

A consistent improvement in neurological status was usually found at subsequent examinations. New or worsening signs could always be attributed to a new clinical event such as an anaesthetic being given or a cardiac arrhythmia. The neurological deficits present in conscious patients at one hour (table III) improved steadily over 48 hours, and very few were still present after this time. In patients who were only rouseable or just responsive, however, similar abnormalities could be elicited as recovery occurred, which usually persisted for five to 10 days.

TABLE III-Disturbances in 25 Conscious Patients One Hour after Cardiac Arrest

\begin{tabular}{l|c}
\hline & No. of Patients \\
\hline Confusional States & 18 \\
Abnormalities of External Ocular Movements: & 10 \\
Gaze palsies & 4 \\
Nystagmus & 2 \\
Lateral rectus paresis & 1 \\
Combinations & 3 \\
Speech Disorders: & 12 \\
Dysarthria & 9 \\
Dysphasia & 2 \\
Dysarthria and dysphasia & 1 \\
Extensor plantars (isolated) & 3 \\
Exacerbation of pre-existing C.N.S. & 6 \\
deficit & \\
\hline
\end{tabular}

\section{Discussion}

Successful resuscitation after cardiac arrest has become common, and with its frequency has grown the practical problem of prognosis in patients who are unconscious or confused.

Clinical assessment is simple and our results indicate that ic is regularly useful in determining outcome. Unconscious patients who did not respond or responded in a nonpurposeful fashion one hour after a cardiac arrest comprised a group with a high mortality $(56 \%)$ and a high risk of intellectual impairment. Patients who responded purposefully at this time, even if feebly, recovered fully, and few died nonneurological deaths (13\%).

The extent to which patients who died affected the results was small. Only one patient in group 1 made any significant neurological recovery before death (all others being unconscious) and, therefore, had he survived he may have been intellectually normal. In group 2 the only patient to die a metabolic death was not fully conscious terminally, and had he survived he may have been intellectually abnormal.

Patients in the post cardiac arrest state showed findings ranging from deep coma to alert consciousness. In group 1, the state of akinetic mutism occurred once, and bizarre posturing appeared in six patients. The neurological lesions res- 
ponsible for the bizarre postures could not be determined during subsequent examinations. One group 2 patient showed a state exactly resembling transient global amnesia. Neurological abnormalities consistently improved in cases who survived.

In this series the incidence of intellectual impairment was high (17\% of all patients, $24 \%$ of survivors). Previous studies suggest that neurological outcome after cardiac arrest is good. These studies were retrospective however, or emphasized satisfactory cardiovascular outcome without careful neurological follow up or considered only patients managed in coronary care areas (where immediate resuscitation is the rule). None of our cases surviving with intellectual impairment suffered their initial cardiac arrest in such an area.

Disparaging claims have been made about the use of clinical assessments in determining outcome after cardiac arrest (Bokonjic and Buchthal, 1961; Pampiglione and Harden, 1968; Plum and Posner, 1972), probably through inadequate documentation of sufficient cases. From our cases it is evident that a patient showing group 1 characteristics at any time more than one hour after cardiac arrest will have a poor prognosis. Two group 1 patients recovered consciousness by four hours, however, and were then not clearly separable from those who survived normally. Therefore an examination at one hour, yields more discriminatory findings.

The nature of the anoxic injury which results in the shortterm disturbances described (table III) is probably a nonstructural intraneuronal (metabolic) defect. The processes which have been found to be disturbed depend on the integrity of large scattered functional groups of cells, and being so they are especially susceptible to environmental disturbances of any sort. The return of these functions over hours or days can be accounted for by a period of intraneuronal repair after withdrawal of the noxious stimulus, similar to other metabolic encephalopathies. Some focal reversible disturbances were seen, but focal features have been described in patients with metabolic encephalopathy (Meyer and Portnoy, 1958; Pearce, 1963; Locke et al., 1961). A vascular-occlusive aetiology of the reversible disturbances is unlikely because most of the disturbances could not be accounted for by a focal lesion, and the rapid resolution of the disturbances contrasts with the delayed or incomplete recovery seen with cerebral infarctions. Cerebral oedema does not account for the transient disturbances either because in this situation it is rare (Brierley, 1961), and it usually manifests itself some time after the arrest, whereas the transient disturbances were present immediately.

Of interest is the absence of some findings which might have been expected. Instances of focal cerebral infarction as commonly occur in patients with vascular disease were not seen in our patients nor did patients show an association of features (pupillary abnormalities, oculomotor signs, papilloedema) suggestive of cerebral oedema. Though the cerebellum is known to be sensitive to anoxia, evidence of cerebellar damage was not present in any of our patients who could adequately be assessed. The rare occurrence of delayed neurological deterioration which has been described by other workers (Plum et al., 1962) was not seen in our cases.

A larger prospective series would almost certainly show that other reversible neurological abnormalities occasionally occur after cardiac arrest and might also serve to establish the optimum time and exact reliability for this clinical method of determining outcome.

The authors wish to thank Dr. R. J. Burns and Dr. A. R. Clarkson, who commented in depth on every aspeot of the text; Dr. J. V. Gordon, Dr. R. J. Burns, and Dr. J. P. Rice, who advised on the protocol for clinical assessment; and the medical staff of the Royal Adelaide Hospital, who gave permission for their cases to be examined.

\section{References}

Binnie, C. D., et al. (1970). British Medical fournal, 4, 265.

Bokonjic, N., and Buchthal, F. (1961). In Cerebral Anoxia and the Electroencephalogram, ed. J. S. Meyer and H. Gastaut, p. 118. Springfield, Thomas.

Brierley, J. B., et al. (1971). Lancet, 2, 560.

Brierley, J. B. (1961). In Cerebral Anoxia and the Electroencephalogram, ed. J. S. Meyer and H. Gastaut, p. 167. Springfield, Thomas.

Dobson, M., et al. (1971). British Medical Fournal, 3, 207.

Hockaday, J. M., et al. (1965). Electroencephalography and Clinical Neurophysiology, 18, 575 .

Johnson, L. A., et al. (1967). American fournal of Cardiology, 20, 831.

Lancet, (1973). 1, 523. Lancet, (1973). 1, 5errill, J. P., and Tyler, H. R. (1961). Archives of Internal
Medicine, 108, 519.

McNamee, B. T., et al. (1970). British Medical fournal, 4, 204.

Meyer, J. S., and Portnoy, H. D. (1958). Neurology, 8, 601

Pampiglione, G., and Harden, A. (1968). Lancet, 1, 1261.

Pearce, J. M. S.' (1963). Postgraduate Medical fournal, 39, 653.

Plum, F., Posner, J. B., and Hain, R. F. (1962). Archives of Internal Medicine,

110, 18.
Plum, F., and Posner, J. B. (1972). The Diagnosis of Stupor and Coma. Philadelphia, Davis.

\section{Introduction}

Intravenous infusion is widely used in hospitals for the administration of bulk fluids, including blood, drugs, and food in liquid form. The standard infusion equipment consists of a bottle or bag containing the fluid to be administered, a plastic administration set, and a suitable cannula for insertion into the vein. Administration sets are manufactured in two basic forms, one for adult use and the other for paediatric use. About 3 million adult sets are used in the U.K. every year.

The standard administration set is gravity-fed, the rate of flow being controlled by a simple plastic regulating clamp. Two alternative methods for the administration of fluids are the pressure pump and the peristaltic pump. The former generally employs a syringe principle, the plunger being driven at a speed selected so that a given volume of fluid is delivered in a 